\title{
Short-term retention in normal and retarded children'
}

\author{
JOSEPH F. FAGAN III \\ UNIVERSITY OF CONNECTICUT
}

To test certain predictions from the Ellis (1963) "stimulus trace" theory, retarded children and equal-MA normals were compared for the short-term retention of digits where length of retention interval (LRI) and amount of retroactive interference (RI) were varied. A Low-IQ defic it as well as an RI effect was demonstrated. There were no reliable IQ by LRI or IQ by RI interactions. Implications for the Ellis theory were discussed.

Ellis (1963) has proposed that a defect in short-term memory characterizes the behavior of retarded individuals. His central hypothesis is that both the amplitude and duration of the stimulus trace, $s_{t}$, for a perceptual event is diminished in the subnormal organism. The impoverished $s_{t}$ is presumably due to a weakened central nervous system integrity, $n_{i}$, in the subnormal organism, i.e., $n_{i}$ serves as a limiting function for $s_{t}$. Some of the indices of $n_{\mathbf{i}}$ suggested are intelligence, mental age, and institutionalization. Since $n_{\mathbf{i}}$ serves as a limit on $s_{t}$ and since $n_{i}$ is assumed to vary with a number of measures such as $I Q$ and $M A$, it seems apparent that various indices of $n_{i}$ should not be confused in tests of the contention that retardates differ from normals in short-term memory.

As Ellis points out, the most appropriate tests of $s_{t}$ theory are in situations where behavior is directly dependent upon short-term memory. Standard digit-span testing, for example, would provide a suitable occasion for a fair test of hypotheses derived from $s_{t}$ theory. If normal and retarded children are compared for the retention of digits where retention intervals are allowed to vary or where interfering material is introduced during the retention interval, the following predictions would be possible: (1) the longer the retention interval, the poorer the performance of the subnormals relative to the normals (in statistical terms, a significant groups by length of retention interval interaction) and (2) the greater the amount of retroactive interference (RI), the poorer the retention of the retardates relative to the normals (a groups by RI interaction).

The purpose of the present experiment was to match normal and retarded children on two measures of $n_{i}$ (MA and institutionalization), allowing IQ to vary, and to test their short-term memory for digits. Length of retention interval and amount of retroactive interference constituted two additional independent variables and the expected effects predicted by $s_{t}$ theory were for a reliable Low-IQ deficit and significant $I Q$ by LRI and IQ by RI interactions.

Method

Subjects. There were seven educable, noninstitutionalized retardates (six males and one female) with no apparent speech or hearing difficulties attending a special day-school for retarded children matched with an equal number of normal school children for sex, MA, and socioeconomic status. The modal social status of both groups was upper-middle-class. Relevant IQ, CA, and MA characteristics of both populations are listed in Table 1. The CA and MA data are represented in months.

Design. A standard digit span technique was used, each message being four digits in length. There were two independent groups of Ss (Normal and Retarded). Each S experienced repeatedly all possible combinations of three recall intervals $(0,4$, or 8 sec.) and two RI conditions, delay intervals filled (F) or delay intervals unfilled (U). The five basic combinations of conditions $(0,4 \mathrm{U}, 4 \mathrm{~F}$, $8 \mathrm{U}, 8 \mathrm{~F}$ ) were given four times to each $\mathrm{S}$ for a total of 20 trials. Each of the four-digit messages was constructed by selecting digits blindly from a random number table with the following restrictions: no number appeared more than once within a message, the digit "zero" was never used and obvious number sequences were avoided. These 20 spans were divided into four lists of five messages each. Each list contained one of each possible combination of conditions $\left(0,4 U_{8} 4 \mathrm{~F}, 8 \mathrm{U}, 8 \mathrm{~F}\right)$. Presentation of these combinations within a list was randomized for each $S$ as was the order of lists over trials.

Procedure. Each S was run individually in a quiet room. Digits were presented orally by $E$ at the rate of approximately one per second. On trials where no interfering material was presented ( $4 \mathrm{U}$ and $8 \mathrm{U}$ ) the Ss simply waited until E said "now" to repeat back the message. On interference trials ( $4 \mathrm{~F}$ and $8 \mathrm{~F}$ ) the Ss were required to name colored cards (red, blue yellow) which were presented by $E$ in a random order, one at a time, approximately one second apart, for either four or eight interpolations.

Prior to test, each $\mathrm{S}$ was told: "This is a game we play to see how well kids remember numbers. You listen carefully and when I say 'now' you say the numbers back to me." $S$ was then given a non-test, fourdigit message and tested for recall. If the child failed the test, the instructions were repeated until it was clear that $S$ understood the procedure. "Very good! Let's try that again, but this time I'm going to wait a little while before I say 'now'. Remember, when I say 'now', you tell me what the numbers were." $\mathrm{S}$ was then tested with another four-digit message with the

Table 1. A summary of chronological age, mental age, and intelligence quotient characteristics of the two populations

\begin{tabular}{lrrrrrr} 
& \multicolumn{3}{c}{ Normals } & \multicolumn{3}{c}{ Retardates } \\
\hline & CA & MA & \multicolumn{1}{c}{ IQ } & CA & MA & IQ \\
\hline Mean & 107.3 & 107.6 & 100.3 & 137.7 & 103.3 & 75.3 \\
SD & 4.4 & 3.9 & 3.6 & 10.5 & 7.4 & 6.1 \\
\hline
\end{tabular}




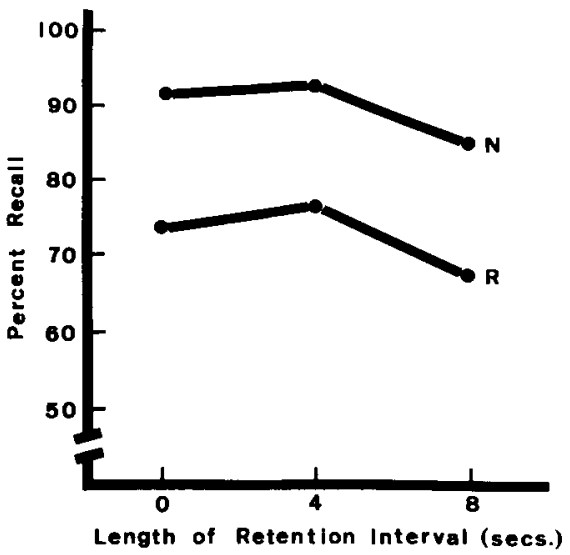

Fig. 1. Percent of messages correctly recalled for normals (N) and retardates $(\mathbf{R})$ under the unfilled condition at each of three retention intervals.

recall interval delayed for approximately three sec. After insuring that $S$ comprehended this part of the task, E went on with: "Good boy (girl)! This time while you're waiting for me to say 'now', I'm going to show you some colors and you tell me what they are. Then, when I say 'now', tell me what the numbers were." $\mathrm{S}$ was then tested with two interpolated colors following a new message. Once it was clear that $S$ understood the task, the experiment proper began. "Fine? Now we're going to play the game for a while. Sometimes I'll show you the colors while we're waiting and sometimes I won't. Sometimes I'll wait to say 'now' and sometimes I won't. Remember, the object of the game is to tell me the numbers when I say 'now'. Ready?"'

On each trial digit recall was S-paced. A typical session lasted about $20 \mathrm{~min}$.

\section{Results and Discussion}

Recall was scored according to the following criterion: one point was given for each digit correctly recalled regardless of position; one additional point was added for each correct digit recalled in the proper position. If, for example, the message were 4-2-7-1

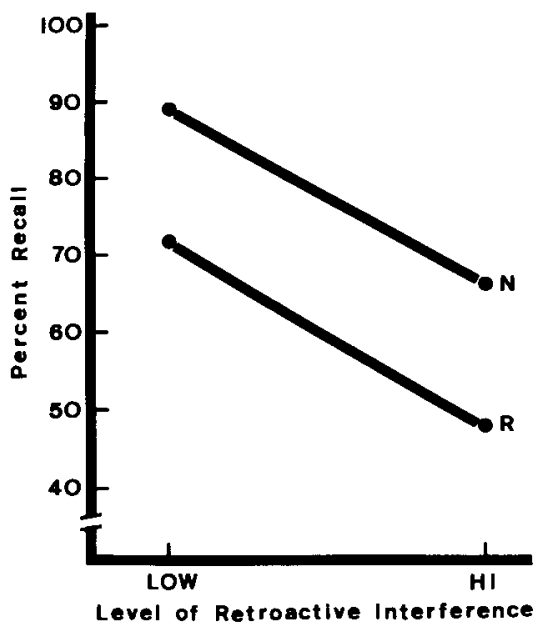

Fig. 2. Percent of messages correctly recalled for normals (N) and retardates $(R)$ for two levels of $R I$. and the response was $4-7-2-1$, the score would be six points. With this scoring system a maximum score was eight and a minimum score zero points for each message. To partial out the effects of LRI and RI and the interactions of these variables with IQ, two analyses of variance were performed. In the first analysis, the scores of normal and retarded Ss were compared over delay intervals $(0,4 \mathrm{U}, 8 \mathrm{U})$. The effect of $\mathrm{IQ}$ was marginally significant $(F=4.22, d f=1 / 12, p<.10)$ as was the effect of LRI $(F=2.62, \mathrm{df}=2 / 24, p<.10)$ while the interaction of IQ and LRI was not significant. Figure 1 gives graphic support to these results.

In the second analysis LRI was collapsed and the two IQ groups were compared for two levels of RI, Low-RI $(4 \mathrm{U}+8 \mathrm{U})$ and $\mathrm{Hi}-\mathrm{RI}(4 \mathrm{~F}+8 \mathrm{~F})$. This analysis yielded a marginally significant IQ effect $(F=3.85$, df $=1 / 12, p<$ $.10)$ a reliable $R I$ effect $(F=40.07, \mathrm{df}=1 / 12, \mathrm{p}<.001)$ and a nonsignificant $\mathrm{IQ}$ by $\mathrm{RI}$ interaction. Figure 2 illustrates these relationships.

The important results of this study for the $s_{t}$ theory of retardation lie in the IQ by LRI and IQ by RI interactions. Ellis, through his assumption that both initial amplitude and duration of the stimulus trace are controlled by an IQ measure of $n_{i}$ would predict these interactions to be significant. The results are contrary to prediction and the hypothesis that the duration of the stimulus trace varies with IQ (with MA controlled) receives no support. It is possible, however, that the initial amplitude of the trace may be a function of $I Q$ as the differences ${ }^{2}$ in recall between the two groups in this study suggest.

To consider these results from a different theoretical viewpoint, we might note Spitz's (1967) recent proposal that the apparent retention deficit of retarded children may be a function of an "organizational" deficit, i.e., retardates may be able to retain a certain amount of material as well as normals but, through an inability to "organize," "categorize," "chunk," etc., may be taking in less information. Spitz's views would imply that variables affecting "storage" such as LRI and RI would not interact with intelligence level but that variables affecting "input" such as organizational strategies would interact with IQ. The former implication seems to be borne out by the present study and Spitz (1967) has presented evidence supporting the latter.

\section{References}

Ellis, N. R. The stimulus trace and behavioral inadequacy. In $\mathbf{N}$. R. Ellis (Ed.), Handbook of mental deficiency. New York: McGraw-Hill, 1963.

Spitz, H. H. The role of input organization in the learning and memory of mental retardates. In N. R. Ellis (Ed.), International review of research in mental retardation. Vol. 2: New York: Academic Press, 1967, in press.

\section{Notes}

1. This investigation was supported (in part) by a Public Health Service training grant (5T1 HD84-03 MR) from (National Institute of Child Health and Human Development), Public Health Service. 2 . Since the $F$ test does not take into account the predicted direction of an effect, a one tailed t test was used to test overall normal retardate differences and the expected Low-IQ deficit was observed $(t=2.00, \mathrm{df}=12, \mathrm{p}<.05)$. 